Article

\title{
Preparation and Properties of Corn Starch/Chitin Composite Films Cross-Linked by Maleic Anhydride
}

\author{
Peng Yin ${ }^{1, *}$, Jinglong Liu ${ }^{1}$, Wen Zhou ${ }^{1}$ and Panxin $\mathrm{Li}^{2,3}$ \\ 1 College of Science, Nanjing Forestry University, Nanjing 210037, China; 13951778290@163.com (J.L.); \\ wenzhounjfu@163.com (W.Z.) \\ 2 Agricultural and Forest Products Processing Academician Workstation, Luohe 462600, China; \\ 15651851089@163.com \\ 3 Post-Doctoral Research Center of Nanjiecun Group, Luohe 462600, China \\ * Correspondence: njyp@njfu.edu.cn; Tel.: +86-25-8542-7621
}

Received: 23 June 2020; Accepted: 14 July 2020; Published: 19 July 2020

\begin{abstract}
To improve the functional properties of starch-based films, chitin $(\mathrm{CH})$ was prepared from shrimp shell powder and incorporated into corn starch (CS) matrix. Before blending, maleic anhydride (MA) was introduced as a cross-linker. Composite $\mathrm{CS} / \mathrm{MA}-\mathrm{CH}$ films were obtained by casting-evaporation approach. Mechanical property estimation showed that addition of $0-7 \mathrm{wt} \%$ MA-CH improved the tensile strength of starch films from 3.89 MPa to 9.32 MPa. Elongation at break of the films decreased with the addition of MA-CH, but the decrease was obviously reduced than previous studies. Morphology analysis revealed that MA-CH homogeneously dispersed in starch matrix and no cracks were found in the $\mathrm{CS} / \mathrm{MA}-\mathrm{CH}$ films. Incorporation of MA-CH decreased the water vapor permeability of starch films. The water uptake of the films was reduced when the dosage of MA-CH was below $5 \mathrm{wt} \%$. Water contact angles of the starch films increased from $22^{\circ}$ to $86^{\circ}$ with $9 \mathrm{wt} \% \mathrm{MA}-\mathrm{CH}$ incorporation. Besides, the composite films showed better inhibition effect against Escherichia coli and Staphylococcus aureus than pure starch films.
\end{abstract}

Keywords: chitin; starch films; maleic anhydride; mechanical property; barrier property; antibiotic property

\section{Introduction}

Starch films have been considered for many years as an alternative polymer material for petroleum-based plastic-related industries due to their inexpensive, renewable, and completely biodegradable properties as well as their potential barrier properties [1-5]. However, starch-based film has a number of disadvantages compared to synthetic plastics such as its brittleness, easy aging, and high hydrophilicity [6]. The absorption of water will accelerate the degradation and recrystallization of starch and lose its mechanical properties. At the same time, as an energy substrate, starch-based plastic will be susceptible to the action of microorganisms especially of fungus and then become useless [7-10].

Some additives were often used to overcome the above problems. The additives mainly included carboxylic acid modifiers [11], inorganic minerals (industrial calcium carbonate, biomass calcium carbonate, and nano-clay) [12-14], polysaccharide nanoparticles such as cellulose, starch, chitin and chitosan, alginate, etc. [15-17]. Reinforcing starch with polysaccharide nanoparticles is an appealing approach since both components are polar by nature and no compatibilization is required [18]. Chitin, a linear polysaccharide composed of (1-4)-linked 2-acetamido-2-deoxy-b-D-glucopyranose units, is the second prevalent form of polymerized carbon in nature. It is totally or partially deacetylated (often above $55 \%$ ) products are named as chitosan. Chitin and chitosan possess remarkable properties-such as low density, large surface, hydrophilicity, chemical reactivity, and antimicrobial activity-and 
thus have been extensively studied for a broad variety of applications in bionanocomposites [19-21]. Chitin or chitosan are reported to be used as matrix or as nanofillers to prepare hydrogel or films that can be strategic for packing, adsorbent, and pharmaceutical applications [22-25].

The use of chitin or chitosan as nanofillers and their effect on the properties of starch films have been well estimated in researches. Properties seem to be dependent on the dosage and the size and shape of the nanofillers. Dosage is a general factor because any filler that exceeds the loading capacity of the matrix will bring about negative effect on the performance of the films. For example, in Qin et al.'s study [26], the tensile strength of maize starch films incorporated with $0.5-2 \%$ chitin nano-whiskers increased from 2.79 to $3.17 \mathrm{MPa}$ but decreased to $2.37 \mathrm{MPa}$ when the dosage of fillers were $5 \%$. The size of chitin/chitosan fillers is another factor. Fillers with high molecular weight are favorable for the improvement of mechanical and barrier properties [27-31]. The aspect ratio of the fillers is another important factor in determining properties of the starch films. Salaberria et al. [27] investigated the role of chitin nanocrystals (CHNC) and nanofibers (CHNF) on properties in thermoplastic starch films. Superior data were found with the S/CHNF samples, in which the tensile strength jumped from 5 to $11 \mathrm{MPa}$ in the starch nanocomposite films incorporated with 5 and $20 \mathrm{wt} \%$ of CHNF. However, as can be observed in the literatures, the increase of tensile strength was often accompanied by the sharp decrease of elongation at break in the composite films which indicated a more fragile behavior $[27,29,30]$. Further improving the properties of starch-based composites became essential.

Aiming to further improve the properties of starch films, thermoplastic starch nano-biocomposite films were prepared using chitin nanoparticles extracted from shrimp shells as fillers $(\mathrm{S} / \mathrm{CH})$ in this study. Maleic anhydrate (MA) was introduced before blending the two matrices and the obtained composite films were named as S/MA-CH. Films without maleic anhydrate incorporation named as $\mathrm{S} / \mathrm{CH}$ were prepared as comparison. The mechanical, thermal, barrier, and antibacterial properties of the composite films were examined to assess the effect of MA-CH nanoparticles on the starch films.

\section{Materials and Methods}

\subsection{Materials}

Normal maize starch (with an amylose content of approximately $32 \pm 1 \%$ ) was obtained from Zhucheng Xingmao Corn Development Co., Ltd. (Tengzhou, Shandong, China). The shrimp shell powder was purchased from Shandong Qilin animal husbandry (Linyi, Shandong, China). Glycerol was supplied by Tianjin Jiangtian Chemical Co. Ltd. (Tianjin, China). All other chemicals used in the present study were of analytical grade.

\subsection{Preparation of Chitin Nanoparticles}

Chitin was isolated from powder of mantis shrimp wastes according to Salaberria et al.'s [29] methods with some modification. Briefly, proteins were first removed using a $2 \mathrm{M} \mathrm{NaOH}$ solution at $25{ }^{\circ} \mathrm{C}$ for $24 \mathrm{~h}$ under vigorous stirring; then, minerals $\left(\mathrm{CaCO}_{3}\right)$ were removed by $2 \mathrm{M} \mathrm{HCl}(37 \%$ $w / w)$ solution at $25^{\circ} \mathrm{C}$ for $3 \mathrm{~h}$; Products from each step were washed with distilled water and filtrated. Pellets were dried at $60^{\circ} \mathrm{C}$ for $12 \mathrm{~h}$ and then dispersed in $3 \mathrm{M} \mathrm{HCl}(37 \% w / w)$ at $100{ }^{\circ} \mathrm{C}$ for $3 \mathrm{~h}$ under reflux for acid hydrolysis, and finally, pigments were extracted using $2 \% \mathrm{KMnO}_{4}$ solution at $50{ }^{\circ} \mathrm{C}$ for $4 \mathrm{~h}$ under vigorous stirring. The obtained products were filtered and washed with distilled water. The resulting chitin nanoparticles were dried at $60^{\circ} \mathrm{C}$ overnight in an oven.

\subsection{Maleic Anhydride Modification and Film Preparation}

The obtained chitin nanoparticles were washed and dried and then dispersed in absolute ethyl alcohol. $5 \%\left(\mathrm{w} / \mathrm{w}\right.$ chitin) maleic anhydride was added to the mixed solution and maintained at $45^{\circ} \mathrm{C}$ for $4 \mathrm{~h}$ under stirring. The solution was then adjusted to $\mathrm{pH} 7.0$ and washed by ethyl alcohol and dried.

Maize starch/MA-chitin composite films (S/MA-CH) were prepared using a solution casting method. Briefly, $3.0 \mathrm{~g}$ of maize starch was dispersed in $100 \mathrm{~mL}$ of deionized water and aliquots of 
MA-CH (0, 1.0, 3.0, 5.0, 7.0, and $9.0 \mathrm{wt} \%$, based on maize starch) were added to the starch suspension. The mixture was stirred for $30 \mathrm{~min}$ at $90^{\circ} \mathrm{C}$, then, $3.0 \mathrm{~g}$ of plasticizer (glycerol) were added and the suspensions were stirred for an additional $30 \mathrm{~min}$ at $90^{\circ} \mathrm{C}$ Finally, the samples were cooled to room temperature and poured into a $10 \times 10 \mathrm{~cm}^{2}$ acrylic mold and dried for $48 \mathrm{~h}$ at $25 \pm 2{ }^{\circ} \mathrm{C}$. Films with unmodified chitosan nanoparticles $(\mathrm{S} / \mathrm{CH})$ were also prepared as control. Sample codes were $\mathrm{S}, \mathrm{S} / \mathrm{CH}$, $\mathrm{S} / \mathrm{MA}-\mathrm{CH}$, respectively. All starch films were preserved in a relative humidity of $70 \pm 2 \%$ chamber at $25 \pm 2{ }^{\circ} \mathrm{C}$ for further testing.

\subsection{Fourier Transforms Infrared Spectroscopy}

The absorbance spectra of the chitin nanoparticles, S/MA-CH composite films were recorded with an infrared spectrometer (VERTEX 70, Bruker, Hamburg, Germany) in attenuated total reflectance (ATR) mode. Powder samples were pressed by potassium bromide. IR spectra were measured at wavelengths from $400 \mathrm{~cm}^{-1}$ to $4000 \mathrm{~cm}^{-1}$.

\subsection{Tensile Measurements}

The tensile tests were performed at room temperature in accordance with the ASTM D638 standard on a testing machine (SANS, MTS Systems Corporation, Shenzhen, China). Five to eight specimens were tested for each sample, and the average values of the measured properties were reported.

\subsection{Contact Angle}

Measurement of the contact angle was carried out at room temperature. The wetting behavior of the samples was measured and analyzed using a contact angle analyzer (DSA100, KRUSS, Hamburg, Germany) and a watered syringe. A drop of water was dropped on the sample, and its angle of incidence was measured soon after deposition using software. Each photo was taken for $0.016 \mathrm{~s}$ to $1 \mathrm{~s}$.

\subsection{Scanning Electron Microscope}

The morphology of the samples was studied on a field emission scanning electron microscope (JSM-7600F, Takeno, Tokyo, Japan). The films were put into liquid nitrogen and its fractured cross-sections were used for SEM analysis. The fractured faces were vacuum coated with gold prior to analysis, and the tungsten filament was operated at $20 \mathrm{kV}$.

\subsection{Differential Scanning Calorimetry and Thermogravimetric Analysis}

DSC thermograms of a sample were recorded by a differential scanning calorimetry analyzer (DSC 204 F1, Netzsth, SELB, Bavaria, Germany). Samples were tested within a temperature range of $30-250{ }^{\circ} \mathrm{C}$ at a heating rate of $10{ }^{\circ} \mathrm{C} / \mathrm{min}$. Thermal stability curves of the samples were recorded on a thermogravimetric analyzer (TG 209 F1, Netzsch, SELB, Bavaria, Germany). The samples were analyzed under a nitrogen atmosphere over a temperature range of $25-600{ }^{\circ} \mathrm{C}$ at a heating rate of $20{ }^{\circ} \mathrm{C} / \mathrm{min}$.

\subsection{Water Uptake}

Films were cut into $20 \times 20 \mathrm{~mm}$ specimens and dried at $105^{\circ} \mathrm{C}$ for $2 \mathrm{~h}$. After being weighed, the specimens were kept in a climate chamber $\left(25^{\circ} \mathrm{C}, \mathrm{RH} 70 \%\right)$, then samples were taken out every $1 \mathrm{~h}$ and weighed until $6 \mathrm{~h}$. The mass gain at each time (W, water uptake) was calculated as: $\mathrm{W}(\%)=\left[\left(\mathrm{W}_{\mathrm{f}}-\mathrm{W}_{0}\right) / \mathrm{W}_{0}\right] \times 100$ where $\mathrm{W}_{0}$ is the sample's initial mass and $\mathrm{W}_{\mathrm{f}}$ is the sample's mass after absorption time.

\subsection{Water Vapor Permeability (WVP)}

WVP was assessed using Dang et al.'s [30] methods with some modifications. Each film was cut into a round shape with a diameter of $22 \mathrm{~mm}$ and then placed on the open mouth of a test cup, 
which had an inner diameter of $20 \mathrm{~mm}$ and contained $8 \mathrm{~g}$ of dried calcium chloride. The films were then sealed to the cup using paraffin wax and placed in an incubator at $25 \pm 2{ }^{\circ} \mathrm{C}$ and $70 \pm 2 \% \mathrm{RH}$ for $2 \mathrm{~h}$ for balance. Then, samples were weighed every $1 \mathrm{~h}$ until $6 \mathrm{~h}$. The WVP was calculated as follows: $\mathrm{WVP}=\mathrm{WVTR} / \mathrm{S}(\mathrm{R} 1-\mathrm{R} 2) \times \mathrm{X}$, where WVTR is the water transmission rate which was determined by the slope of the linear portion of a plot of weight gained versus time $(\mathrm{g} / \mathrm{h}), \mathrm{R} 1$ and $\mathrm{R} 2$ is the RH of incubator and test cup, respectively. $\mathrm{X}$ is the film thickness $(\mathrm{m}), \mathrm{S}$ is the saturated water vapor pressure (Pa).

\subsection{Antibacterial Activity}

Antibacterial activities of starch films (control sample), and representative S/MA-CH composite films were examined as inhibitory effects against the growth of Gram-positive bacteria, Staphylococcus aureus, and Gram-negative bacteria, Escherichia coli. To study the antibacterial activities, changes in the growth of $S$. aureus and E. coli incubated in the broth medium were investigated following Qin et al.'s [26] methods. All strains from agar slant were aseptically inoculated in LB broth and subsequently incubated at $37^{\circ} \mathrm{C}$ for $12 \mathrm{~h}$ under mild shaking, then, an inoculum $(100 \mu \mathrm{L})$ of S. aureus and E. coli were aseptically transferred to $50 \mathrm{~mL}$ of LB broth containing film samples $\left(2 \times 2 \mathrm{~cm}^{2}\right)$ and shaking at $37^{\circ} \mathrm{C}$ for $12 \mathrm{~h}$. The inhibitory effect was estimated by measuring the turbidity of the cultured medium at $600 \mathrm{~nm}$ using a spectrophotometer. The medium from shaking flask after $12 \mathrm{~h}$ cultivation was diluted $100,000 \times$ and transferred to agar plate and incubated at $37^{\circ} \mathrm{C}$ for another $12 \mathrm{~h}$, the colony growth on the plate were recorded.

\section{Results and Discussion}

\subsection{Mechanical Properties}

To investigate the effect of MA-CH on the mechanical properties of starch films, different percentages of MA-CH were incorporated into starch matrix to prepare S/MA-CH films. Starch films filled with the same concentration of $\mathrm{CH}$ were also prepared to make comparison. The tensile strength and elongation at break of all films were determined and the results were shown in Figure 1. Obviously, all starch films filled with chitin nanofillers became more resistant to the tensile. The tensile strength of films filled with 1-7 wt \% MA-CH increased from 5.82 to $9.32 \mathrm{MPa}$. The pure starch film has a tensile strength of $3.89 \mathrm{MPa}$. As a comparison, the tensile strength of starch films with $7 \mathrm{wt} \% \mathrm{CH}$ was $8.36 \mathrm{MPa}$. This is in accordance with the results of previous reports in which chitin or chitosan nanofillers were incorporated [31-33]. As described in the literature, the improvement of tensile strength was often attributed to the intermolecular hydrogen bonding between chitin and starch chains and the efficient stress transfer from the matrix to the chitin nano-size fillers.
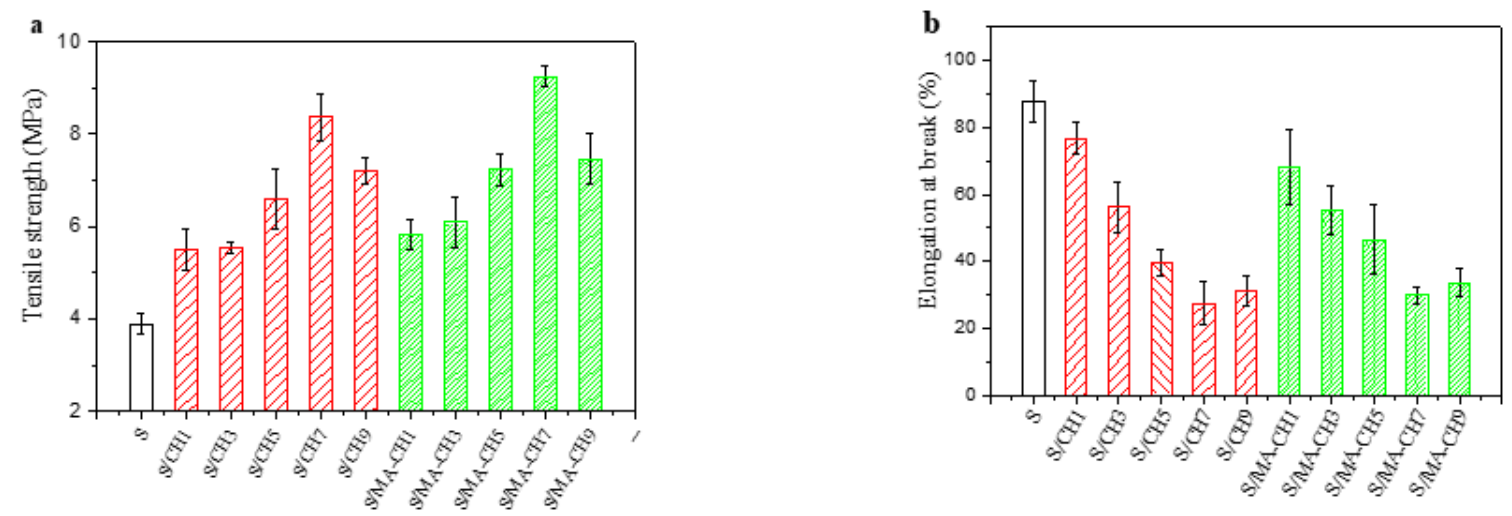

Figure 1. Tensile strength (a) and elongation at break (b) of S films, $\mathrm{S} / \mathrm{CH} 1 \%$ films, $\mathrm{S} / \mathrm{CH} 3 \%$ films, S/CH 5\% films, S/CH 7\% films, S/CH 9\%, S/MA-CH 1\% films, S/MA-CH 3\% films, S/MA-CH 5\% films, S/MA-CH 7\% films, and S/MA-CH 9\% films. 
The slight decrease of tensile strength of the composite films with $9 \mathrm{wt} \% \mathrm{CH}$ or MA-CH could be attributed to aggregation of the fillers which exceeded the loading capacity of starch matrix. This is in agreement with the results of Qin [26] and Chang [32] in which the tensile strength of the composite films decreased when the dosage of chitin nanoparticles exceeded $6 \mathrm{wt} \%$ and $1 \mathrm{wt} \%$ respectively. The loading capability of the starch matrix may be dependent on the size and shape of the fillers. The elongation at break of the starch films decreased with the $\mathrm{CH}$ incorporation, but remained $30 \%$ when the concentration of MA-CH was $7 \mathrm{wt} \%$ (the pure starch films is $87 \%$ ) (Figure $1 \mathrm{~b}$ ). The superior mechanical property of the starch films incorporated with $\mathrm{MA}-\mathrm{CH}$ nanoparticles was due to the cross-linking effect between chitin and starch by maleic anhydrate incorporation. This is also found in Wu et al.'s study in which citric acid was used as a crosslinker between starch and chitosan [34]. The tensile test curves were provided as supplementary (Figure S1).

\subsection{Reaction Mechanism}

Figure 2 shows the ATR-FTIR spectra of chitin, starch films, and composite S/MA-CH films incorporated with different concentration of MA- $\mathrm{CH}$. The starch films exhibited their characteristic bands including the $3276 \mathrm{~cm}^{-1}$ (O-H stretching), $2925 \mathrm{~cm}^{-1}$ (C-H stretching), $1651 \mathrm{~cm}^{-1}$ (bound water), $1148 \mathrm{~cm}^{-1}$ (C-O stretching) of starch which is correspond to the results of Lopez et al. (2014) [28] and Dan et al. (2016) [30]. The bands of chitin nanoparticles were also typical and were in agreement with those reported by Palpandi et al. (2009) [35] for $\alpha$-chitin from shrimp. The bands at $3448 \mathrm{~cm}^{-1}$ corresponded to the stretching of $\mathrm{N}-\mathrm{H}$ which was overlapped with the band of $\mathrm{O}-\mathrm{H}$ stretching at $3363 \mathrm{~cm}^{-1}$ [36]. The band at $2930 \mathrm{~cm}^{-1}$ was attributed to the $\mathrm{CH}_{3}$ and $\mathrm{CH}_{2}$ stretching and the one located at $2857 \mathrm{~cm}^{-1}$ to $\mathrm{CH}$ bonds. The presence of amide I and II groups were evidenced by bands at 1663 and $1583 \mathrm{~cm}^{-1}$, respectively. Besides, other bands were identified at $1421 \mathrm{~cm}^{-1}\left(\mathrm{CH}_{3}\right.$ deformation and $\mathrm{CH}_{2}$ bending), 1088 and $892 \mathrm{~cm}^{-1}$ (ring stretching), $1030 \mathrm{~cm}^{-1}$ (CO).

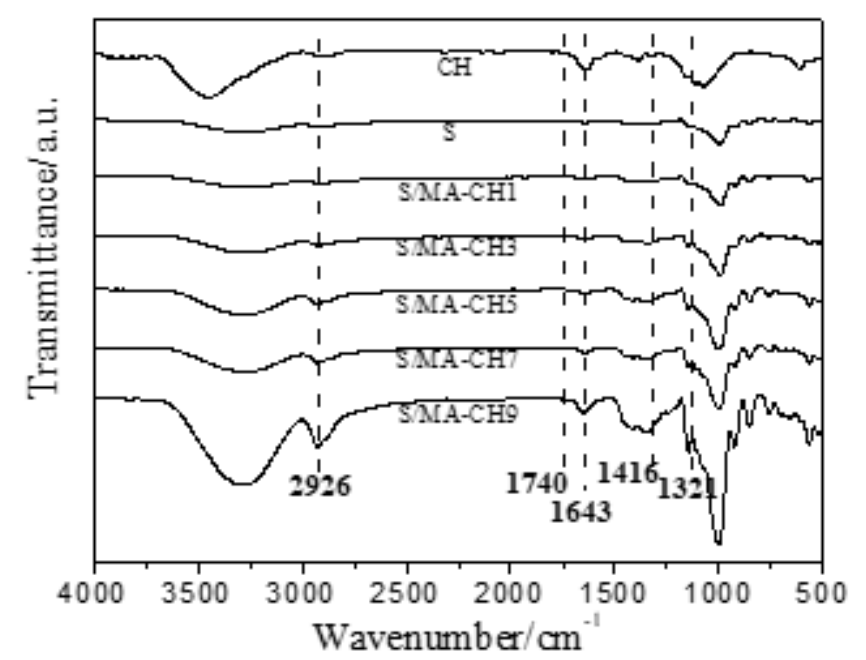

Figure 2. ATR-FTIR spectra of chitin nanoparticle (CH), starch films (S), S/CH $1 \%$ films, S/CH 3\% films, $\mathrm{S} / \mathrm{CH} 5 \%$ films, S/CH 7\% films, S/CH 9\%, S/MA-CH 1\% films, S/MA-CH 3\% films, S/MA-CH 5\% films, S/MA-CH 7\% films, and S/MA-CH 9\% films.

Incorporation of MA-CH did not significantly affect the spectra pattern of starch films, but some bands became more intense with the MA- $\mathrm{CH}$ incorporation. The strengthened bands mainly included $3426,2926,1146,1643,1416$, and $1008 \mathrm{~cm}^{-1}$ and were due to the increment of some functional groups of both starch and MA-CH. For example, the more intensive and sharp band at 2926 and $1416 \mathrm{~cm}^{-1}$ was due to the increase of $\mathrm{C}-\mathrm{H}$ bonds, and the intensities of the bands at 1643 and $1321 \mathrm{~cm}^{-1}$ gradually increased with the incorporation of MA-CH nanoparticles due to the presence of amine and carboxyl groups ( $\mathrm{N}-\mathrm{H}$ and $\mathrm{C}=\mathrm{O}$ ), respectively. Hydrogen bonding between starch and chitin molecules was 
expected but was difficult to evaluate from the spectra characterized at room temperature due to the effect of moisture [37]. Only a little shift of the band at $3276 \mathrm{~cm}^{-1}$ was observed in the spectrum indicative of hydrogen bonding formation between chitin and starch. The band at $1740 \mathrm{~cm}^{-1}$ (stretching of $\mathrm{C}=\mathrm{O}$ ) which was also increased with the increasing of $\mathrm{MA}-\mathrm{CH}$, indicated the increased crosslinking reaction between MA and polysaccharides. A similar phenomenon was also found in Wu et al.'s study in which they used citric acid as cross-linker in starch-chitosan composite films [34].

\subsection{Morphological Characterization}

Micrographs of the representative starch and starch-based composite films (S, S/CH3, S/CH7, S/MA-CH3, and S/MA-CH7) were presented in Figure 3. All images were taken from the fragile fractured surface of the films. It can be seen that the starch films without nanofillers have a uniform and smooth fracture surface, some cracks were observed which indicated a fragile property of the film. Incorporation of chitin nanoparticles in the starch matrix make the cross-sections look a little rough and a lot of wrinkles appeared. Meanwhile, cracks still appeared which indicated that incorporation of chitin nanoparticles did not improve the flexibility of starch films. When MA was introduced, the cross-section of the films became uniform and no cracks were observed. A scheme of the potential interactions between starch and MA-CH was also shown in the Figure. There are two kinds of probable intermolecular binding between the matrixes: (1) hydrogen bonding between the OH groups of starch backbone and the $\mathrm{OH}$ and residual $\mathrm{NH}_{2}$ groups at the surface of chitin; (2) covalent bonding between the carboxyl group of maleic anhydride and the $\mathrm{OH}$ groups of starch; (3) covalent bonding between the carboxyl group of maleic anhydride and the $\mathrm{OH}$ or residual $\mathrm{NH}_{2}$ groups of chitin nanofillers.

A


B


Figure 3. A. SEM photographs (1000× amplification) of starch film (a), S/CH $3 \%$ film (b), S/CH 7\% film (c), S/MA-CH 3\% film (d), S/MA-CH 7\% film (e); B. illustrative scheme of S/MA-CH films. Scale bars indicate $50 \mu \mathrm{m}$. 


\subsection{Thermal Analysis}

DSC curves of starch films and S/MA-CH films were presented in Figure 4a. No glass transition or melting of polymers was observed in the temperature range analyzed. All films showed one single endothermic peak, corresponding to water evaporation [34]. The blend films showed a longer melting distance, which is in accordance with many other researches about starch films filled with nanofillers [26,31]. The maximum of the water evaporation peak decreased with the addition of 1-7 wt \% MA-CH, but increased when the dosage of MA-CH is $9 \mathrm{wt} \%$. This incident can be described in terms of intermolecular forces. When MA-CH was added, the hydrogen bonds between starch chains were destroyed and became weaker which made the water evaporation easier; However, more intermolecular bonds between starch and MA-CH were formed when the concentration of MA-CH reached $9 \mathrm{wt} \%$.
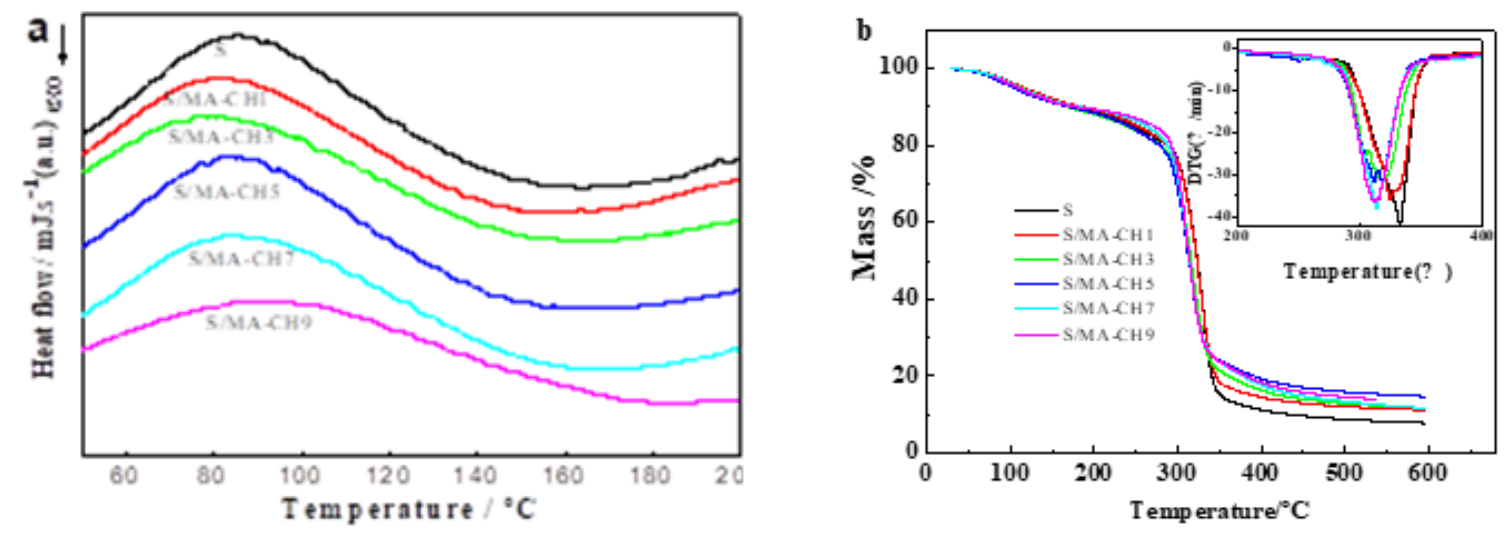

Figure 4. DSC thermograms (a) and thermogravimetric (TGA) and derivative thermograms (DTG) (b) of S films, S/CH 1\% films, S/CH 3\% films, S/CH 5\% films, S/CH 7\% films, S/CH 9\%, S/MA-CH 1\% films, S/MA-CH 3\% films, S/MA-CH 5\% films, S/MA-CH 7\% films, and S/MA-CH 9\% films.

To further explore the thermal stability of the S/MA-CH films, thermogravimetric analysis was carried out and the results were shown in Figure $4 \mathrm{~b}$. All the films displayed two stages of thermal degradation. The first stage is the weight loss below $200{ }^{\circ} \mathrm{C}$, which is mainly manifested as the vitalization of small molecules such as glycerol and water, as also shown in Figure 4 . The second stage of weight loss in the temperature range $200-400{ }^{\circ} \mathrm{C}$ was attributed to dehydration of saccharide rings, depolymerization, and decomposition of the polymers [38]. The DTG curve in Figure $4 \mathrm{~b}$ showed the maximum rate of degradation temperature of each film. It can be seen that with the addition of MA- $\mathrm{CH}$, the maximum degradation temperatures decreased gradually from $332{ }^{\circ} \mathrm{C}$ to $312{ }^{\circ} \mathrm{C}$, indicating a negative effect of MA-CH on the thermal stability of starch films. This may be due to: (1) the lower thermostability of MA-CH; (2) the destruction of crystalline structure of starch because of the reaction between the two carbohydrate polymers. A similar phenomenon was also observed in Salaberria et al.'s study in which they prepared starch composite films filled with chitin nanocrystals by melt-mixing or solution casting methods and all films filled with chitin nanocrystals showed a decreased thermostability $[27,29]$.

\subsection{Contact Angle}

The water contact angle of the starch film and composite S/CH films with or without MA were measured and presented in Figure 5. All data were recorded soon after dropping. Starch films without nanofillers showed a contact angle of $22^{\circ}$. With the addition of $\mathrm{CH}$ nanofillers, the water contact angle decreased firstly, and then increased when the dosage of $\mathrm{CH}$ was above $5 \mathrm{wt} \%$. The films with $9 \mathrm{wt} \% \mathrm{CH}$ nanofillers have a contact angle of $57^{\circ}$. The decrease of the contact angles of the films at the beginning maybe due to the break of the intermolecular bonds of starch chains with nanofiller incorporation. Then, with the increment of the $\mathrm{CH}$ dosage, interaction between chitin and starch chains 
(e.g., hydrogen bonding) was formed, and the surface hydrophobicity of the $\mathrm{S} / \mathrm{CH}$ films increased. When MA was introduced, cross-linking occurred between polymers, and hydrophobic groups such as $\mathrm{C}=\mathrm{O}$ and $\mathrm{C}=\mathrm{C}$ provided high water resistance for the films. As a result, obvious increment of water contact angle of the composite films was observed. This is in accordance with the study of Wu et al. (2019) [34] in which citric acid was introduced to potato starch/chitosan composite films. Formation of hydrophobic eater groups between MA and the polysaccharides leads to a decrease in the number of polar groups on the surface. In addition, it has been reported that the increased surface roughness will be helpful in improving the surface contact angle due to heterogeneous wetting [39]. The increased surface roughness of MA cross-linked S/CH films was also observed in the SEM images as shown in Figure 5.

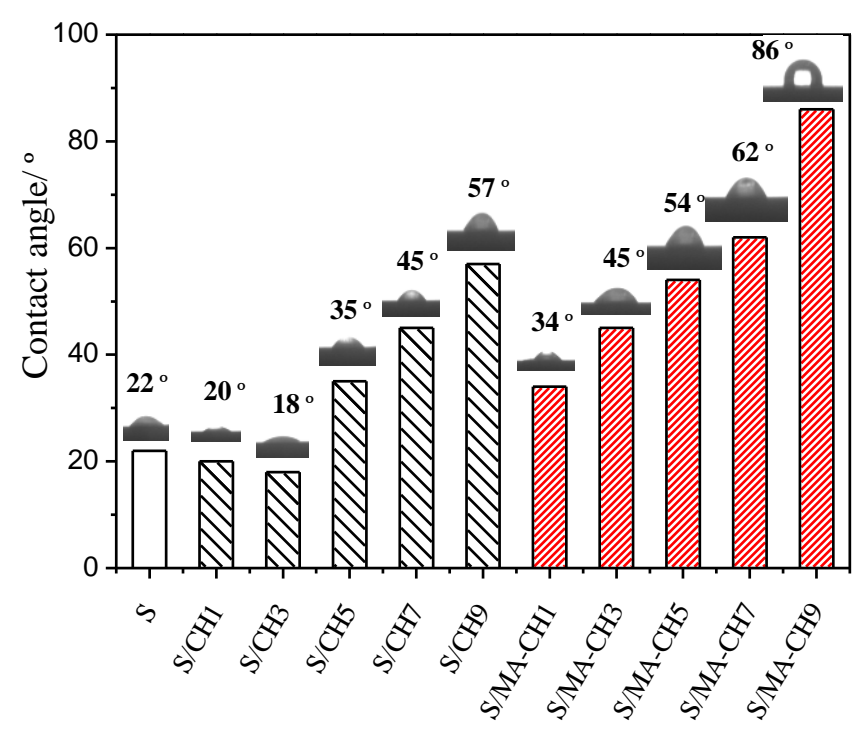

Figure 5. Water contact angle of S films, S/CH 1\% films, S/CH 3\% films, S/CH 5\% films, S/CH 7\% films, S/CH 9\%, S/MA-CH 1\% films, S/MA-CH 3\% films, S/MA-CH 5\% films, S/MA-CH 7\% films, and S/MA-CH $9 \%$ films.

\subsection{Water Vapor Permeability and Moisture Absorption}

It is well known that the poor barrier property of starch films limited their applications. In this study, water vapor permeability (WVP) of the S/MA-CH films was determined to investigate the effect of MA-CH incorporation on the barrier property of starch films (shown in Figure 6a). It can be seen that the WVP value decreased sharply when $1 \mathrm{wt} \% \mathrm{MA}-\mathrm{CH}$ was incorporated and then increased slightly with the increasing of MA-CH dosage. However, all the blend films showed a lower WVP value compared with the pure starch films. The relative hydrophobicity of chitin as compared with that of starch and the cross-linking reaction between polymers may be the obstruction for water vapor transmission, and this was also confirmed by the higher water contact angle of TPS/MA-CH films than that of the neat starch film (Figure 5). This result was in agreement with Salaberria et al.'s [27] study, in which the WVP value of starch films decreased when 5 and $10 \mathrm{wt} \%$ chitin nanocrystal were added. Changes of the crystal structure of starch films and thus change the path of water vapor permeability because of the addition of chitin nanofillers may be the reason. Moreover, the replacement of hydrophilic hydroxyl groups with hydrophobic ester groups caused by cross-linker in this study is also the reason [40], and it can also explain the higher water contact angles of the S/MA-CH films than that of the S/CH films without maleic anhydride incorporation. 
a





Figure 6. Water vapor transmission rate (a) and water uptake (b) of S films, $\mathrm{S} / \mathrm{CH} 1 \%$ films, $\mathrm{S} / \mathrm{CH} 3 \%$ films, S/CH 5\% films, S/CH 7\% films, S/CH 9\%, S/MA-CH 1\% films, S/MA-CH 3\% films, S/MA-CH 5\% films, S/MA-CH 7\% films, and S/MA-CH 9\% films.

The moisture absorption of the films was also investigated and shown in Figure $6 \mathrm{~b}$. The moisture absorption of starch films decreased when $1 \mathrm{wt} \%$ of MA-CH was added, then increased with the increasing concentration of MA-CH. The decrease of moisture absorption at the beginning may be due to the cross-linking between MA-CH and starch, which reduces the polarity and reduces the interaction between hydrophilic groups and water. Similar results were also found by [34] in which they used citric acid as crosslinker in potato starch/chitosan composite films. However, with the increasing of MA-CH dosage (above $7 \mathrm{wt} \%$ ), the polar groups such as hydroxyl groups increased, and the water resistance reduced.

\subsection{Antibiotic Activity of Composite Films}

All the films filled with chitin nanoparticles showed higher anti-mildew ability than the pure starch films (data shot shown). In this study, the antibacterial activities of the starch and S/MA-CH composite films were estimated. S. aureus and E. coli were selected for testing which were familiar Gram-positive bacteria and Gram-negative bacteria, respectively. The optical density (OD, absorbance at $600 \mathrm{~nm}$ ) of culture medium including the starch or composite starch films was measured after inoculated by the microorganisms. Composite starch films filled with $5 \mathrm{wt} \%$ and $7 \mathrm{wt} \%$ of MA-CH were chosen for estimation and the results were shown in Figure 7a. The corresponding colony growth on agar plate was shown in Figure $7 \mathrm{~b}$. Since the ODs of the medium increased with the growth of microorganisms, lower absorbance at $600 \mathrm{~nm}$ indicated higher antibacterial activity of the test material [26]. Obviously, both of the growth of S. aureus and E. coli was suppressed in the suspensions contained S/MA-CH films. It is in agreement with Lopez et al.'s study [28]. Films with 5 wt \% CH or MA-CH concentration showed superior antibacterial activities than that with $7 \mathrm{wt} \%$ nanofillers. As depicted in literature, the antimicrobial mechanism of the films could be due to the interactions between positively charged chitin and negatively charged bacterial cell membranes, which results in increased membrane permeability and eventually causes the rupture and leakage of the material [41]. In this study, no obvious differences were observed in the antimicrobial activities of the $\mathrm{S} / \mathrm{CH}$ composite films against E. coli and S. aureus. The limitation of antibacterial activity may be due to the weak migration of chitin from the film to the broth, and the higher surface hydrophobic property of the S/MA-CH films which impede the adhesion of microorganism may be another factor [42]. 



Figure 7. Inhibitory effect (a) of $\mathrm{S}$ films, $\mathrm{S} / \mathrm{CH} 5 \%$ films, $\mathrm{S} / \mathrm{CH} 7 \%$ films, S/MA-CH 5\% films and S/MA-CH 7\% films against S. aureus and E. coli, and pictures of agar plates (b) inoculated by $100 \mu \mathrm{L}$ of diluted broth from the corresponding flask. Pictures were taken after $24 \mathrm{~h}$ of cultivation.

\section{Conclusions}

Thermoplastic starch-based nano-biocomposite films with superior mechanical property, higher surface hydrophobicity, and barrier properties were successfully prepared by introducing chitin nanoparticles as fillers and maleic anhydride as cross-linker. Introduction of chitin nanoparticles and their good dispersion in thermoplastic starch matrix were confirmed by ATR-FTIR and FE-SEM analysis.

The properties improvement was due not only to the rigid and hydrophobic properties of chitin nanoparticles which was derived from shrimp shell wastes, but also to the strong adhesion between starch and chitin and cross-linking reaction via maleic anhydride. The mechanical and barrier properties of the nano-biocomposites are related to the nanofillers load. The films cross-linked by maleic anhydride especially displayed better mechanical properties and higher water contact angles than the composite films without cross-linker. The films with MA-CH incorporation showed better antibacterial capabilities than the pure starch films, and thus have potential application for packaging or products requiring delayed biodegradation. 
Supplementary Materials: The following are available online at http://www.mdpi.com/2073-4360/12/7/1606/s1.

Author Contributions: P.Y. conceived and designed the experiments; J.L., W.Z., and J.L. performed the experiments; P.L. significantly contributed materials/reagents/analysis tools; P.Y. wrote the manuscript, with revisions made by P.Y. All authors have read and agreed to the published version of the manuscript.

Funding: This research was funded by higher school in Jiangsu province college students' practice innovation training programs, grant number 201910298025Z. The APC was also funded by $201910298025 \mathrm{Z}$.

Acknowledgments: The authors thank the Analysis and Testing Center, Nanjing Forestry University for providing the experimental equipment used in this study.

Conflicts of Interest: The authors declare no conflict of interest.

\section{References}

1. Doane, W.; Swanson, C.; Fanta, G. Emerging polymeric materials based on starch. ACS Symp. Ser. 1992, 476, 197-230.

2. Avella, M.; De Vliegar, J.J.; Errico, M.E. Biodegradable starch/clay nanocomposites films for food packaging applications. Food Chem. 2005, 93, 467-474. [CrossRef]

3. Lorcks, J. Properties and applications of compostable starch-based plastic material. Polym. Degrad. Stab. 1998, 59, 245-249. [CrossRef]

4. Ghanbarzadeh, B.; Oromiehi, A.R. Thermal and mechanical behavior of laminated protein films. J. Food Eng. 2009, 90, 517-524. [CrossRef]

5. Khan, B.; Niazi, M.B.K.; Samin, G.; Jahan, Z. Thermoplastic starch: A possible biodegradable food packaging material-a review. J. Food Process Eng. 2017, 40, e12447. [CrossRef]

6. Averous, L.; Fringant, C.; Moro, L. Starch-based biodegradable materials suitable for thermoforming packaging. Starch Starke 2001, 53, 368-371. [CrossRef]

7. Smits, A.L.M.; Kruiskamp, P.H.; van Soest, J.J.G.; Vliegenthart, J.F.G. Interaction between dry starch and plasticisers glycerol or ethylene glycol, measured by differential scanning calorimetry and solid state NMR spectroscopy. Carbohydr. Polym. 2003, 53, 409-416. [CrossRef]

8. Teixeira, E.D.; Pasquini, D.; Curvelo, A.A.S.; Corradini, E.; Belgacem, M.N.; Dufresne, A. Cassava bagasse cellulose nanofibrils reinforced thermoplastic cassava starch. Carbohydr. Polym. 2009, 78, 422-431. [CrossRef]

9. Niazi, M.B.K.; Zijlstra, M.; Broekhuis, A.A. Understanding the role of plasticisers in spray-dried starch. Carbohydr. Polym. 2013, 97, 571-580. [CrossRef]

10. Niazi, M.B.K.; Broekhuis, A.A.; Broekhuis, A.A. Influence of plasticizer with different functional groups on thermoplastic starch. App. Polym. Sci. 2015, 132, 42012. [CrossRef]

11. Amirah, H.M.Z.; Mohamad Kahar, A.W.; Hanafi, I. Biodegradation behaviour of thermoplastic starch: The roles of carboxylic acids on cassava starch. J. Polym. Environ. 2018, 26, 691-700.

12. Munlika, B.; Kaewta, K. Biodegradation of thermoplastic starch/eggshell powder composites. Carbohydr. Polym. 2013, 97, 315-320.

13. Munlika, B.; Kaewta, K. Biodegradability, mechanical, and thermal properties of thermoplastic starch/cuttlebone composites. Polym. Composite. 2015, 36, 1401-1406.

14. Mohan, T.P.; Devchand, K.; Kanny, K. Barrier and biodegradable properties of corn starch-derived biopolymer film filled with nanoclay fillers. J. Plast. Sheet. 2017, 33, 309-336. [CrossRef]

15. Salaberria, A.M.; Labidi, J.; Fernandes, S.C.M. Chitin nanocrystals and nanofibers as nano-sized fillers into thermoplastic starch-based biocomposites processed by melt-mixing. Chem. Eng. J. 2014, 256, 356-364. [CrossRef]

16. Terrazas-Hernandez, J.A.; Berrios, J.D.; Glenn, G.M.; Imam, S.H.; Wood, D.; Bello-Perez, L.A.; Vargas-Torres, A. Properties of cast films made of chayote (sechium edule sw.) tuber starch reinforced with cellulose nanocrystals. J. Polym. Environ. 2015, 23, 30-37. [CrossRef]

17. Tomasz, O.; Agnieszka, W.; Leszek, M.; Marcin, M.; Karol, K.; Andrzej, K.; Grzegorz, B. Effect of natural fibres on the mechanical properties of thermoplastic starch. Int. Agrophys. 2016, 30, 211-218.

18. Dufresne, A.; Castano, J. Polysaccharide nanomaterial reinforced starch nanocomposites: A review. Starch/Stärke 2017, 69, 1500307. [CrossRef]

19. Zeng, J.B.; He, Y.S.; Li, S.L.; Wang, Y.Z. Chitin whiskers: An overview. Biomacromolecules 2012, 13, 1-11. [CrossRef] 
20. Zhai, M.L.; Zhao, L.; Yoshii, F.; Kume, T. Study on antibacterial starch/chitosan blend film formed under the action of irradiation. Carbohydr. Polym. 2004, 57, 83-88. [CrossRef]

21. Weska, R.F.; Moura, J.M.; Batista, L.M.; Rizzi, J.; Pinto, L.A.A. Optimization of deacetylation in the production of chitosan from shrimp wastes: Use of response surface methodology. J. Food Eng. 2007, 80, 749-753. [CrossRef]

22. Bertolino, V.; Cavallaro, G.; Lazzara, G.; Milioto, S.; Parisi, F. Halloysite nanotubes sandwiched between chitosan layers: Novel bionanocomposites with multilayer structures. New J. Chem. 2018, 42, 8384-8390. [CrossRef]

23. Salvo-Comino, C.; Rassas, I.; Minot, S.; Bessueille, F.; Arab, M.; Chevallier, V.; Rodriguez-Mendez, M.L.; Errachid, A.; Jaffffrezic-Renault, N. Voltammetric sensor based on molecularly imprinted chitosan-carbon nanotubes decorated with gold nanoparticles nanocomposite deposited on boron-doped diamond electrodes for catechol detection. Materials 2020, 13, 688. [CrossRef] [PubMed]

24. Freire, T.M.; Fechine, L.M.U.D.; Queiroz, D.C.; Freire, R.M.; Denardin, J.C.; Ricardo, N.M.P.S. Magnetic porous controlled $\mathrm{Fe}_{3} \mathrm{O}_{4}$-chitosan nanostructure: An ecofriendly adsorbent for efficient removal of azo dyes. Nanomaterials 2020, 10, 1194. [CrossRef]

25. Lisuzzo, L.; Cavallaro, G.; Parisi, F.; Milioto, S.; Fakhrullin, R.; and Lazzara, G. Core/shell gel beads with embedded halloysite nanotubes for controlled drug release. Coatings 2019, 9, 70. [CrossRef]

26. Qin, Y.; Zhang, S.L.; Yu, J.; Yang, J.; Xiong, L.; Sun, Q.J. Effects of chitin nano-whiskers on the antibacterial andphysicochemical properties of maize starch films. Carbohydr. Polym. 2016, 147, 372-378. [CrossRef]

27. Salaberria, A.M.; Diaz, R.H.; Labidi, J.; Fernandes, S.C.M. Role of chitin nanocrystals and nanofibers on physical, mechanical and functional properties in thermoplastic starch films. Food Hydrocoll. 2015, 46, 93-102. [CrossRef]

28. Lopez, O.; Garcia, M.A.; Villar, M.A.; Gentili, A.; Rodriguez, M.S.; Albertengo, L. Thermo-compression of biodegradable thermoplastic corn starch films containing chitin and chitosan. LWT Food Sci. Technol. 2014, 57, 106-115. [CrossRef]

29. Mendes, J.F.; Paschoalin, R.T.; Carmona, V.B.; Sena Neto, A.R.; Marques, A.C.P.; Marconcini, M.; Mattoso, L.H.C.; Medeiros, E.S.; Oliveira, J.E. Biodegradable polymer blends based on corn starch and thermoplastic chitosan processed by extrusion. Carbohydr. Polym. 2016, 137, 452-458. [CrossRef]

30. Dang, K.M.; Yoksan, R. Morphological characteristics and barrier properties of thermo plastic starch/chitosan blown film. Carbohydr. Polym. 2016, 150, 40-47. [CrossRef]

31. Valencia-Sullca, C.; Vargas, M.; Atares, L.; Chiralt, A. Thermoplastic cassava starch-chitosan bilayer films containing essential oils. Food Hydrocoll. 2018, 75, 107-115. [CrossRef]

32. Chang, P.R.; Jian, R.J.; Yu, J.G.; Ma, X.F. Starch-based composites reinforced with novel chitin nanoparticles. Carbohydr. Polym. 2010, 80, 420-425. [CrossRef]

33. Xie, F.; Pollet, E.; Halley, P.J.; Averous, L. Starch-based nano-biocomposites. Prog. Polym. Sci. 2013, 38, 1590-1628. [CrossRef]

34. Wu, H.; Lei, Y.; Lu, J.; Zhu, R.; Xiao, D.; Jiao, C.; Xia, R.; Zhang, Z.; Shen, G.; Liu, Y.; et al. Effect of citric acid induced crosslinking on the structure and properties of potato starch/chitosan composite films. Food Hydrocoll. 2019, 97, 105208. [CrossRef]

35. Palpandi, C.; Shanmugam, V.; Shanmugam, A. Extraction of chitin and chitosan from shell and operculum of mangrove gastropod Nerita (Dostia) crepidularia Lamarck. Int. J. Med. Sci. 2009, 1, 198.e205.

36. Rinaudo, M. Chitin and chitosan: Properties and applications. Prog. Polym. Sci. 2006, 31, 603.e632. [CrossRef]

37. Dang, K.M.; Yoksan, R. Development of thermoplastic starch blown film by incorporating plasticized chitosan. Carbohydr. Polym. 2015, 115, 575-581. [CrossRef]

38. Mathew, S.; Abraham, T.E. Characterisation of ferulic acid incorporated starch chitosan blend fifilms. Food Hydrocoll. 2008, 22, 826-835. [CrossRef]

39. Xiong, R.; Han, Y.; Wang, Y.; Zhang, W.; Zhang, X.; Lu, C. Flexible, highly transparent and iridescent all-cellulose hybrid nanopaper with enhanced mechanical strength and writable surface. Carbohydr. Polym. 2014, 113, 264-271. [CrossRef]

40. Garavand, F.; Rouhi, M.; Razavi, S.H.; Cacciotti, I.; Mohammadi, R. Improving the integrity of natural biopolymer films used in food packaging by crosslinking approach: A review. Int. J. Biol Macromol. 2017, 104, 687-707. [CrossRef] 
41. de Azeredo, H.M.C. Nanocomposites for food packaging applications. Food Res. Int. 2009, 42, $1240-1253$. [CrossRef]

42. Mishra, G.; Mittal, N.; Sharma, A. Multifunctional mesoporous carbon capsules and their robust coatings for encapsulation of actives: Antimicrobial and antibioadhesion functions. ACS Appl. Mater. Interfaces 2017, 9 , 19371-19379. [CrossRef] [PubMed] 